\title{
Insights from Implementing a System for Peer- Review
}

\author{
Christian Lundquist, Martin Skoglund, Karl Granström and Torkel Glad
}

\section{Linköping University Post Print}

\section{Tweet}

N.B.: When citing this work, cite the original article.

C2013 IEEE. Personal use of this material is permitted. However, permission to reprint/republish this material for advertising or promotional purposes or for creating new collective works for resale or redistribution to servers or lists, or to reuse any copyrighted component of this work in other works must be obtained from the IEEE.

Christian Lundquist, Martin Skoglund, Karl Granström and Torkel Glad, Insights from Implementing a System for Peer-Review, 2013, IEEE Transactions on Education, (56), 3, 261-267.

http://dx.doi.org/10.1109/TE.2012.2211876

Postprint available at: Linköping University Electronic Press http://urn.kb.se/resolve?urn=urn:nbn:se:liu:diva-96893 


\title{
Insights from Implementing a System for Peer-Review
}

\author{
Christian Lundquist, Martin A. Skoglund, Karl Granström, and Torkel Glad
}

\begin{abstract}
Courses at the Master's level in automatic control and signal processing cover mathematical theories and algorithms for control, estimation and filtering. However, giving students practical experience in how to use these algorithms is also an important part of these courses. A goal is that the students should not only be able to understand and derive these algorithms, but also be able to apply them to real life technical problems. The latter is achieved by assigning more time to the laboratory tutorials, and designing them in such a way that the exercises are open for interpretation; an example of this would be giving the students more freedom to decide how to acquire the data needed to solve the given exercises. The students are asked to hand in a laboratory report in which they describe how they solved the exercises. This contribution presents a double blind peer-review process for laboratory reports, introduced at the department of Electrical Engineering at Linköping University, Sweden. A survey was administered to students and the results are summarized in this work. Also discussed are the teachers' experiences of peerreview, and of how students perform later in their education in writing their Master's theses.
\end{abstract}

Index Terms-Critical thinking, laboratory work, peer review, peer assessment student learning, student self-assessment, teambased projects

\section{INTRODUCTION}

$\mathbf{S}$ CIENTIFIC publications are usually peer-reviewed by other researchers before being published. Despite the fact that this is a major part of scientific work, students rarely practice giving criticism and presenting their point of view clearly [1]. This publication describes a peer-review process applied to lab reports in automatic control and signal processing courses at Linköping University (LiU). To the best of the authors' knowledge, this paper is the first to evaluate the introduction of such a process in these specific subjects. The assumption underlying the introduction of the process was that if the students were required to read, question and assess their fellow students' reports, as well as to propose and communicate alternative solutions, they would be forced to spend more time on the task. Through the repeated exposure to the subject matter content they would thereby acquire an increased understanding of the subject.

The engineering profession is practical, and the aim of the engineering education is to prepare students for their working life. In the education system, it is only in the lab that students are confronted with practical exercises. Labs can be divided into three types, depending on their purpose [2]. A development lab is used by engineers who need experimental

The authors are with the Department of Electrical Engineering, Linköping University, 58283 Linköping, Sweden. E-mail: \{lundquist,ms,karl,torkel\}@ isy.liu.se. data to design and specify their products, and to validate that the products meet requirements. General questions are analyzed in a research lab, without there being a certain product in mind. An education lab is aimed at transmitting to students a body of knowledge that practicing engineers are expected to master. The intention at $\mathrm{LiU}$ has been that in the last years of the Master of Science program the labs should be a bit closer to research labs, thus moving away from the traditional education labs with predefined solutions. Peerreview of the students' lab reports was introduced in 2010 as a part of this move towards more research-like labs. Courses in signal processing and automatic control comprise a mixture of theory and practice. In the labs the students are asked to use their obtained theoretical knowledge to solve practical problems. This requires significant effort and understanding of the subject; a peer-review process allows the students to deepen this understanding. Further, the existing course design, including a lab section with written report, is well suited for introducing a peer-review system very similar to a journal paper review system.

Most electrical engineering students at Linköping University do their Master's theses in companies, rather than, say, a university research group. In companies they are typically given various real life problems to solve, and it is important for them to be prepared for this. The labs in the advancedlevel courses are deliberately designed, within the limits of the available time and resources, to be as similar as possible to a real life technical problem that students may encounter during their Master's theses and future careers. Writing technical reports is commonplace at many companies, and the lab reports serve as a preparation for this. Thus if peer-review can improve students writing skills, it is likely to prove of future benefit to them as they tackle real life engineering problems. These improved writing skills are also benefit the students when they write their Master's theses.

The peer-review process includes giving and receiving criticism, and justifying one's position in a comprehensible way. Topping [3] gives a good overview of the literature and how the parameters to be considered in a peer-review process should be used. Such parameters include whether the reviewers grade papers, or give written or oral assessments. Other parameters are the degree of teacher involvement in the process, the degree of anonymity, and so on. The students appreciate their work being reviewed by several people, rather than just the teacher; they believe that this can provide a fairer assessment [3], and they can often get more detailed feedback on their work. Disadvantages include the potential for embarrassing situations, and that the process is more 


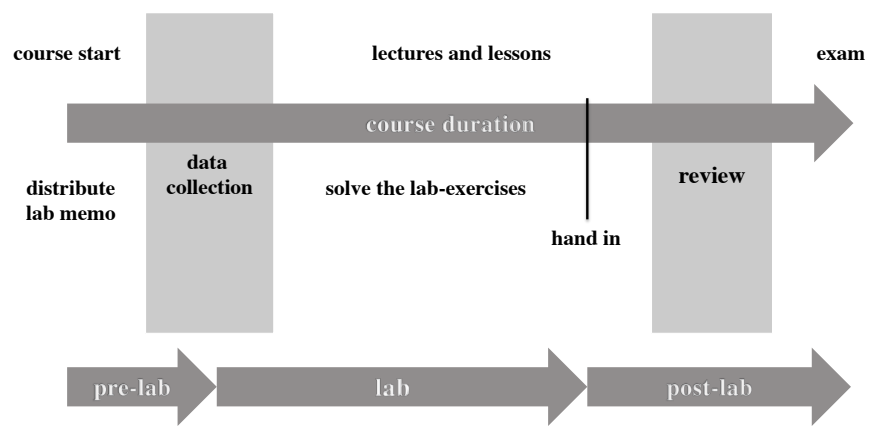

Fig. 1. Course structure. Data collection is part of the pre-lab, students then perform the actual lab; peer-review is part of the post-lab.

demanding and strenuous, and less accurate, than if the teacher does the job.

The article is organized as follows: Section II discusses literature related to this work. Section III describes how the labs and the peer-review process are organized. Section IV summarizes and discusses the results from interviews with students and teachers, a student survey and comments from course evaluations. Finally, Section V draws conclusions and gives directions for future work.

\section{RELATED LITERATURE}

Before the authors started to design and implement the peerreview process a literature survey was performed; the results, and their relevance to this study, are described here.

\section{A. Laboratory Work}

The lab is an integral part of the course; this should be emphasized by pre- and post-lab elements in the course [4], [5]. In the courses discussed here, the pre-lab is the data collection that happens at the start of the courses, before students have been taught the material required to perform the lab exercises. Then throughout the course the students perform the exercises in groups, using the data they collected themselves. This creates opportunities for them to process data and perform laboratory work on their own, whenever they choose. The post-lab element is the peer-review process, Fig. 1.

The main objective of laboratory work is, according to Kirschner and Meester [6], to teach general methods that students will use in their professional lives. To teach laboratory skills is of great benefit to laboratory technicians, but less beneficial for graduate engineering students. Hofstein and Luneta [4] refer to a number of studies showing that much of the time in the laboratory is devoted to coping with technical details, which limits the time that can be used for meaningful learning. Students rarely remember details; instead, the time is better used if students manage to obtain fundamental insights into the subject, which can be applied to other problems in their professional lives. For this reason, in the LiU labs, the data collecting equipment and software is already prepared so that during the pre-lab the students only have to focus on the experimental design, such as where to place sensors for optimal data collection.
Laboratory work is usually less formal than traditional classroom teaching, creating other social conditions, particularly as regards the interaction between students and teachers. Hofstein and Luneta [4], [7] refer to a number of studies showing that students learn more when collaborating than when working on their own. Colosi and Zales [8] are critical of formal labs and show that cooperation and student involvement is important for optimal learning. By letting the students collect their individual datasets in the LiU courses, they can cooperate in finding solutions. Since the datasets differ between groups, they cannot copy each other's solutions, but are only able to discuss conceptual questions with each other.

If student performance is not assessed it may lead to the lab being seen as a less important part of a course. According to [9] this depends largely on teachers' lack of experience in assessing student performance in the lab fairly. Feedback and understanding that occur in the assessment are important, but in reality a teacher often grades pass or fail, without commenting on the student's choice, methods or mistakes. The authors view the peer-review process as a method to increase feedback.

\section{B. Peer-Review in Education}

Topping and Ehly [10] describes various forms of assessment. Open criticism of the essay form is considered more valuable than the scores. In a more formal process where students are asked to write a review report, the students tend to become more responsible and think about their questions and criticisms carefully. When students compare others' work with their own, they will often reassess their own work, discover weaknesses and identify opportunities for improvement. Peerreview should also be conducted throughout the course, rather than at the end. These ideas have been adapted in the LiU courses, and peer-review is included as a post-lab within the course.

Berry and Fawkes [11] investigated how peer-review affected lab report writing in two chemistry courses. Their previous impressions were that the quality of the students' writing was often poor. Theorizing that students are more likely to improve their writing when they know that the target audience is their peers rather than the teaching staff, see e.g., [12], a peer-review system was implemented. Mainly positive comments were received, most students feeling that reviewing others was better than being reviewed. Berry and Fawkes intentionally tried to avoid creating an atmosphere in which students graded and assessed each other, and as a consequence they no longer distribute the reviews to the reviewed students. Berry and Fawkes conclude that the students who participated in peer reviewing improved their writing skills.

When designing a peer-review process it must consider what is standard and what is reference. Since there is no archive of good reports, and no sample reports are provided, students must assess each other's reports on their own initiative. This assessment is thus very likely to vary. It is important that the teacher clearly communicates what is considered important in the assessment [10]. Liu et al. [1] and Trautmann [13] suggest guidelines or instructions that students must follow 
when carrying out the assessment; these instructions were used as a basis for the guidelines to the students in the LiU course lab handouts. Pelaez [14] used a system where students are encouraged to read and evaluate three reference statements, then to compare their evaluation with a professional evaluation, before being allowed to assess each other's reports. Woods [15] presents an iterative approach to detect and correct bias in the assessment.

An aspect of peer-review seldom elaborated on is how best to match reviewers and authors. This is typically done by random assignment. Crespo et al. have considered an adaptive strategy for assigning reviewers to authors [16]. The worstcase scenario is a student with difficulties reviewing another student with difficulties, because neither benefits much from the experience. This was not considered in the LiU courses, since it would have required setting up student profiles in advance.

Many of the theses presented above are based on assumptions and experience. There are only few studies on the effects of peer-review. Pelaez [14] compared students who completed a problem-based task plus peer-review with students who learned the same material in a classical way with lectures and exercises. The former performed better on the test than the latter. Trautmann [13] conducted a comprehensive study on students who subsequently had the opportunity to resubmit their work. She shows that students who carry out peer-review are more likely to update, revise and improve their own work for a second submission, than are students who only review their own work. She also examined the impact of obtaining criticism versus criticizing others. Students who receive criticism are more likely to revise their reports. Eibeck [17] describes a review system for courseware, which is supposed to be made available in a database. A side effect of the peer-review procedure is that reviewers may pick up innovative ideas and incorporate them into their own work. Topping [3] describes a study in which students assessed each other's work. Half the group received feedback on the assessment; half did not. The group was subsequently asked to improve their work and submit it again. There turned out to be no significant difference between groups. This shows the effect of "learning by assessing". Liu et al. [18] analyze the learning effects and student perception of peer-review. Student performance was enhanced when their work is peer-reviewed; they also displayed higher-level thinking skills such as critical thinking, planning, monitoring and regulation. McGourty [19] had students work in team-based projects and rate themselves and each other through a computer-based survey. McGourty concluded that students can play an active role in their own development and assessment. A special use of peer-review can be found in software engineering, [20]. Here the aim is to scrutinize another person's code to discover programming errors and improve quality. Since this is used with great success in many companies, it is argued that it should also be an important part of the engineering education.

There are different opinions on whether peer-review saves teacher resources. Topping [3] concluded that in the short term, before the system has been established, it requires more resources than expected. These resources will be moved from

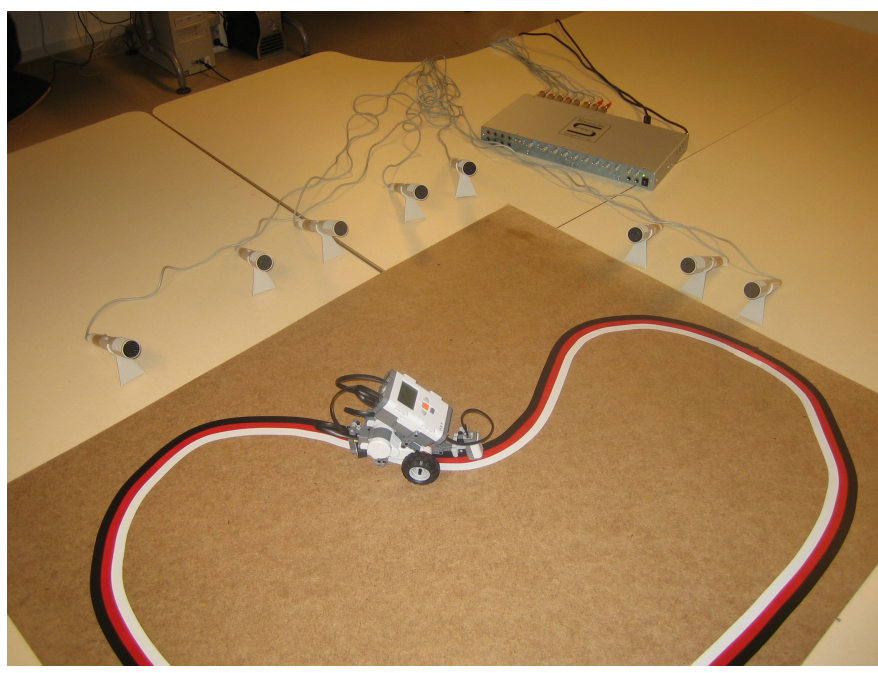

Fig. 2. Example of a data collection setup in the Sensor Fusion course. The moving robot emits a sound impulse, and the students are supposed to estimate the position and motion based on collected microphone data. The students are free to position the microphones wherever they like on the table.

the actual assessment of work to organizing, monitoring and mentoring the students. However, students' review reports and questions let the teachers gain new insights into the students' understanding, learning and their perceptions of course goals. For these reasons, the teachers are allocating resources to supervising students in the LiU courses so as to detect promptly systematic errors in the process. Carlson et al. report experiences from introducing peer-review into an engineering design course [21], using a Web-based environment called Calibrated Peer-Review (CPR). They report that using CPR is initially labor-intensive, but that the procedure becomes easier with time. The teachers' return on this time-investment comes in the form of written assignments being treated more seriously.

\section{Performing the Lab and Peer-Review}

Peer-review was introduced in three courses, Sensor Fusion, Modeling and Simulation and Digital Signal Processing, each corresponding to six ECTS (European Credit Transfer and Accumulation System) credits, offered in the last two semesters of the Electrical and Computer Engineering Master's of Science programs at LiU. In each course one laboratory session was chosen to include the peer-review task. The students work in pairs, and in each case two groups collect data together, see Fig. 2 for an sample setup. The students are assigned a number of tasks to solve beforehand, to gives them time to think over and plan the experimental design before they arrive at the lab session. The lab handout does not give detailed instructions, with the result that the experiments and the results vary between groups.

The organization of the review process mimics that undergone by a journal article, providing the additional motivation that this is something they might be confronted with in their professional life. The steps of the review process are:

1) The students perform the lab, solve the set tasks, and then describe the experimental design, its implementa- 
tion, and their calculations and results in a lab report. They do not affix their names to the report, to ensure a double blind process.

2) The lab reports are sent to the course assistant, who serves as an Editor-in-Chief (EiC).

3) After having briefly checked the content of the reports, the EiC distributes them to a randomly chosen group of students, who are given a few days to read and assess them, and to write a review report, which again is anonymous.

4) The students send their review reports to the EiC, who distributes them, with the corresponding lab reports, to the teachers involved, who here serve as Assistant Editors (AE).

5) The AEs read the lab and review reports, summarize their impressions and assign grades: pass, supplementary examination or fail.

6) The review reports and teachers' assessments are sent to the groups.

Since the students are not used to writing reviews, the lab handout gives review instructions, so that as far as possible the review reports should be of a similar form and quality. To mimic professional review processes as found in scientific journals, for instance, the written review report is in the format of an essay, obliging students to think about not only what to write, but also how to formulate the criticism.

The instructions in the handout ${ }^{1}$ explain that the review report should give useful criticism and constructive comments, use a positive tone and courteous language, and point out strengths as well as weaknesses. They should also comment on the data collection, the proposed solution, whether the ideas presented are well supported by data and theory, and point out particularly interesting and good solutions, as well as needed improvements. The students must submit their reports to a powerful, commercial online plagiarism checker $^{2}$, which reports its findings to the course assistant. The tool being frequently used in Swedish universities discourages students from plagiarism.

\section{RESULTS}

Results of applying the laboratory work peer-review process in the three courses over two years are summarized here, based on surveys, and on interviews with both students and teachers.

\section{A. Student Survey}

The students' experiences are an important source for evaluation and further improvement of the labs and the peerreview process. An eleven-item survey with multiple-choice or graded responses to statements and free text answers, was given to the students in the Sensor Fusion course. Only 12 out of 40 students answered the survey, corresponding to a response rate of 30 percent. Responses were on a Likert scale

\footnotetext{
${ }^{1}$ See course homepages of the three courses with peer-review: Sensor Fusion http://www.control.isy.liu.se/student/tsrt14/, Modeling and Simulation http://www.control.isy.liu.se/student/tsrt62/ and Digital Signal Processing http://www.control.isy.liu.se/student/tsrt78/.

${ }^{2}$ See www.urkund.com, July 30, 2012
}

from 1 (strongly disagree) to 5 (strongly agree); the scores are summarized in Fig. 3. The students' spent an average of 28 hours performing the lab and another eight hours writing the lab report.

Since the Sensor Fusion course is likely to be one of a student's last courses in their program, 11 out of 12 of the students who answered the survey had already participated in a course with peer-review. This particular sensor fusion lab is rather ideal for peer-review, because it can be performed independently of other groups, and solved in many different ways. This is partly confirmed by the free text answers, e.g., "It is good that you have to do all the steps because it gives you a better understanding of the whole lab" and "Hard to know where to begin. Some advice would have been nice". The students having to decide how to solve the lab can lead to some initial frustration, because they might not get started as fast as in other labs.

For the peer-review, most students gave positive responses to having to read other groups' reports, but some responses were less enthusiastic, e.g., "It depends on the quality of the report you receive". This is unavoidable, since if all reports are subject to peer-review, there will always be lower-quality reports.

In the first round of LiU peer-review courses, the peerreviews were given to the report's student authors, along with brief teachers' comments. An early student response to this practice stated it was insufficient to receive comments from a peer (i.e., another student) but only an assessment (pass, fail, completion) from the teacher. The students did not like the feeling of being assessed by other students; they wanted to hear the extensive teachers' comments. This is quite similar to the findings in [11], mentioned above, which found that the quality of reviews was improved if the students knew that they would only be read by a teacher and not by the report's author.

The students experienced the lab as more free, because they had a lot of liberty to decide for themselves how to solve the problems. The students also found the lab to be more extensive than most other labs. Some students appreciate being given independence in the lab, while others want more advice. An encouraging answer was: "You understand more of the course content. You try harder compared to a lab without peerreview”.

\section{B. Course Evaluations}

After every course at Linköping University, students are encouraged to fill out a course evaluation. This serves as an important quality indicator to both teachers and students, either for certain elements, such as labs, lectures and course alignment, or for the course as a whole. One of the statements in the course evaluations is: "This course has assisted in developing my skills in written and oral communication”. Examining the evaluations for the three years before and two years after introduction of peer-review, for the Modeling and Simulation course the average number of "yes" answers was $30 \%$ without peer-review and $53 \%$ after peer-review was introduced; for the Digital Signal Processing course the 
The lab is relevant for the course.

The design of the lab is good.

Knowing that the labreport would be peer-reviwed affected the report quality positively.

To give feedback by peer-reviewing another groups report gave me a deeper understanding of the course content.

To receive feedback from the peers regarding my report gave me a deeper understanding of the course content.

To receive feedback from the teachers regarding my report gave me a deeper understanding of the course content.

To receive feedback from the teachers regarding my review report gave me a deeper understanding of the course content.

I feel that the knowledge I have obtained during the lab, including the review process, is something that will be useful

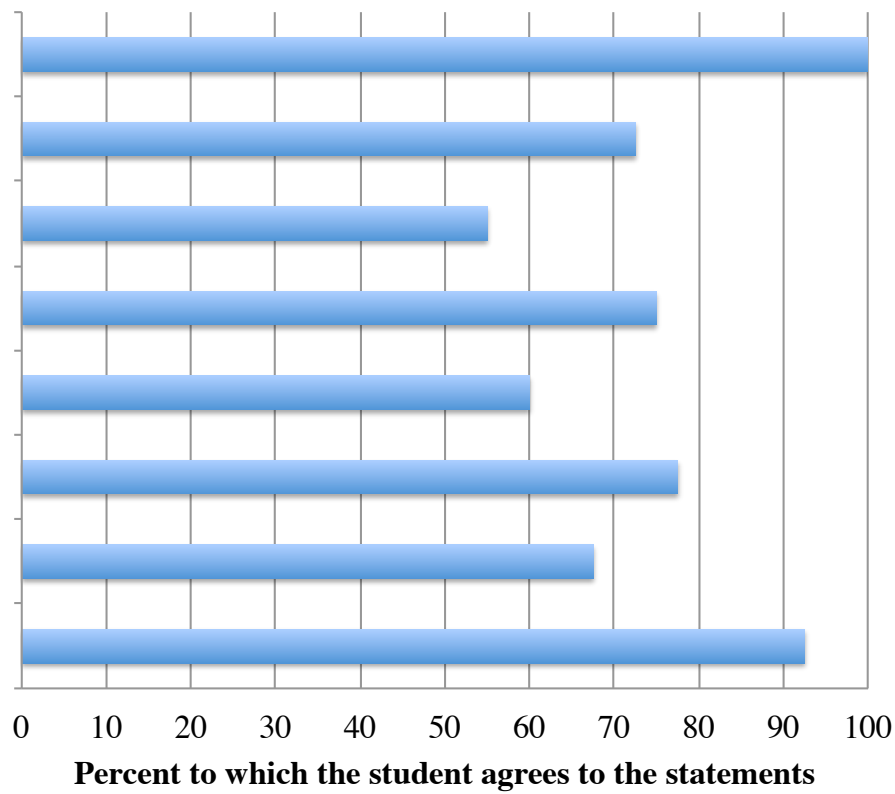

Fig. 3. Responses to the student survey.

corresponding figures are $35 \%$ and $68 \%$ respectively. In these courses there were 395 students during the three years before peer review, of whom $53 \%$ answered the course evaluation, and 274 students, with $47 \%$ answering, during the two years after. The Sensor Fusion course is new, and had peer review from the beginning, so a similar comparison cannot be carried out there. Caution must be used in interpreting these figures, since other changes in the courses were also made during these years, but they are consistent with the free text answers given below. These are not categorized by course.

"The peer-review process is good."

"I appreciate reviewing other peoples' reports"

"An excellent exercise in writing reports. It is rewarding to obtain feedback from fellow students and teachers. It is also rewarding to give feedback to another student group."

"The structure of the labs was nice since we got to practice problem solving, report writing and reviewing reports."

"The part with writing the report and receiving feedback was very rewarding."

"It is good to review other students' reports. You learn a lot and at the same time you will put a bit more effort into your own report."

"It's good to write a report, the peer-review process is also good and it will be useful for coming courses and my Master's thesis project."

"Only receiving comments from a peer, with very few comments from the teachers, is inadequate. We are much more interested in the teachers' opinions of our work, than our peers' opinions."

The students seem positive about peer-review labs in general. In fact, there was no criticism to be found in the course evaluations regarding the peer-review labs. These findings are similar to the results presented by Carlson et al [21], who reported that their students found peer-review difficult at first, but then came to value the experience.

An interesting observation is the last student quote listed above, which can be understood as saying that while the students appreciate peer reviewing, they are ultimately seeking the teachers' opinions, not their peers' opinions. Berry and Fawkes also elaborate on this issue [11], and as mentioned above do not distribute the peer-reviews to the students to avoid giving them the impression of being graded and assessed by other students.

\section{Interview with Two Students}

In addition to the student surveys and course evaluations, students who had participated in courses with peer-review, and also had written their Master's thesis, were sought for interviews. Because the peer-review system had only recently been introduced the number of potential interviewees was limited, and only two students were willing to participate. Such a low number is insufficient to draw statistical conclusions, but the answers and experiences of the two students are an interesting complement to the surveys and evaluations.

The two students, who will be labeled "Larry" and "Morgan", were questioned about their experiences of working with peer-review, and how it affects writing skills. The interviews were held at the very end of their education, one year after having finished courses with peer-review and after they had written their respective Master's thesis. Larry and Morgan were asked:

1) Do you think that reviewing another groups' lab report gave you new knowledge of how a report should be written?

2) Do you think that receiving a review of your lab report from another group gave you new knowledge of how a report should be written? 
On the first question, Larry answered that he definitely gained new knowledge of how to write a report by reviewing another groups' report. Partly because it gave new perspectives on the subject that the report was about, and partly, and above all, because he was able to see structural differences and similarities with his own report. For question two, Larry did not feel that it gave as much new knowledge to be reviewed as being the reviewer. The reason is that the review he received mainly pointed out factual or typing errors, rather than commenting on the structure and outline of his report. Thus, it did not give very much new knowledge of report writing to be reviewed. Finally, Larry pointed out that he thinks peer-reviewing is a valuable part of course work, and could be introduced at an earlier stage in engineering education to give students more time to practice both writing and reviewing reports.

Morgan thinks all forms of practice are good when it comes to writing academic reports, and he explicitly states that constructive criticism is always positive. Peer reviewing gave beneficial information on the outline and structure of a good report, as well as how important it is to use correct language. For himself, he felt that by the time he wrote his Master's thesis, he already had quite a lot of writing experience from high school and university courses, but there were still things to learn. Morgan also felt that it was a little late, introducing peer reviewing during the last part of the degree program.

In summary, both Larry and Morgan think that the peerreview process had a positive effect on their abilities to write and structure a report, and that it would be beneficial to introduce the peer-review process as early as possible in the program.

These findings are in line with those of [11] and [13], that peer-review has a positive influence on report writing. It depends on the individual whether reviewing another report, or having your own report reviewed, is most beneficial. The writing instructions given to the students appear to be quite important, [11] and [13]; the writing quality aspect of the LiU laboratory instructions could probably benefit from further attention.

\section{Interview with Teachers}

The seven teachers involved in peer-review courses were interviewed, to understand how the labs work in practice. These are summarized below, and some conclusions drawn.

1) What is your impression of the quality of the lab reports? The reports are more concise now, but sometimes it seems like the students' write too much just to make sure that they cover what they believe should be in the report. The best reports do not get better, but the average level is better, and the writing is better, which reduces the teachers' workload. Because the labs are more independent, and the students know that their peers will read the reports, they spend more effort monitoring and commenting on the collected data. Before the peerreview process was introduced some students did not even check the collected data before they used it to estimate variables and parameters. If the input is wrong the solution will also be wrong, and the only way to prevent such mistakes is by monitoring the collected dataset before starting to use it in calculations.

2) What is your impression of the quality of the review reports?

In general, the quality is good and the students appear to be rather honest, which perhaps can be explained by anonymity of the review process. The reviews also reflect the students' knowledge, since they need to understand, explain and criticize someone else's work. Other impressions are that the reviews could emphasize shortcomings and mistakes by being more critical, less negative and clearer.

3) How big is the workload for the teachers with this type of lab?

It can be easier to read a lab report using the comments in the review report, however a poor review gives extra work and you have to match the contents of the lab report and review report. Some teachers' tend to read the lab reports as carefully as if they didn't have the review reports.

4) What are the unique benefits of having labs of this form? There is a lot of freedom in how to perform the lab, and there are no unique correct answers. More independence in the labs requires the students to reflect upon their work. Also, it seems that questions and discussion tend to be of a more fundamental character and the review gives more repetition that facilitates further learning. The students get more insight in how the theoretical methods can be used as practical tools if they are used correctly and in the right order. By letting the students find out and describe their procedure, i.e., collecting data, monitoring data, pre-processing data and computing results based on the data, they get a deeper understanding. In the peerreview they see how their peers have performed, they repeat the methods and gain more knowledge.

5) What are the shortcomings of having labs of this form? It is not as easy for students to ask the teachers questions, however this could also be a good thing. The students never have the option to respond to the review and report comments they receive. There can be terrible mismatches in the review process if, for instance, a poor group is asked to review a poor report. On the other hand, there can also be terrific matches leading to a knowledge leap for both parties. This is not a suitable format for all kinds of labs, and at its current form it requires more administration from the teachers involved.

6) What improvements can be made?

There is a need for better instructions, both to students and teachers, and better report templates for the students to use. An obvious improvement would be in the administration, where some kind of submission portal, like the ones for scientific articles, could reduce the teachers' workload.

The teachers reported a shift in the workload from reading reports to administration of the peer-review process; Carlson et al reported similar teacher reactions [21]. They found that 
peer-review administration becomes easier when the course is given multiple times. The initial extra time spent on peerreview is rewarded with an increased report quality.

The teachers who were interviewed for this paper also emphasized that a Web-based tool for peer-review administration would be a great improvement. Such tools have been used previously with good results, see e.g., [18], [19], [21].

The peer-review process cannot be applied to every lab in every course; it must be put into a context, and a large degree of variety and independence in the inter-student solutions must be expected. To handle a lab well when only given general instructions, students need sufficient self-confidence when working in the lab, and must be well prepared and possess adequate knowledge of the course material. This is why a peer-review process is more useful, and achieves better results, in the later stages of the education. Currently the authors have no plans to extend the peer-review process to courses other than the three mentioned here.

\section{CONClusion}

Peer-review has been introduced as a laboratory task in three $\mathrm{LiU}$ engineering program courses; the following conclusions can be drawn:

- The system can easily be implemented in the existing course design.

- In advanced courses in electrical engineering that cover both theory and practice, letting the students apply their knowledge practically and revising this knowledge via a peer-review process gives a deeper understanding of the theory.

- The student response is essentially positive.

- The teachers involved in the courses are also positive, but some fear that the teacher workload might increase.

- There are indications that the quality of the student reports has improved.

Suggestions to improve the overall quality of the labs include:

- Collaborate between courses to create general guidelines for both students and teachers.

- Provide better administrative tools to handle the reports and the grading.

The Linköping University practice of handing out the reviews to the authors could possibly be discontinued to improve the implemented peer-review system.

\section{ACKNOWLEDGMENT}

The authors would like to thank all the teachers in the Automatic Control group at Linköping University who contributed to this work. Your feedback is important.

\section{REFERENCES}

[1] J. Liu, D. T. Pysarchik, and W. W. Taylor, "Peer review in the classroom," BioScience, vol. 52, no. 9, pp. 824-829, Sep. 2002.

[2] L. D. Feisel and A. J. Rosa, "The role of the laboratory in undergraduate engineering education," Journal of Engineering Education, vol. 94, pp. 121-130, Jan. 2005.
[3] K. Topping, "Peer assessment between students in colleges and universities," Review of Educational Research, vol. 68, no. 3, pp. 249-276, 1998.

[4] A. Hofstein and V. N. Lunetta, "The laboratory in science education: Foundations for the twenty-first century," Science Education, vol. 88, no. 1 , pp. $28-54$, Dec. 2004.

[5] H. Hult, "Laborationen - myt och verklighet," Linköpings Universitet, Centrum f'or Universitetspedagogik, Linköping, Sverige, CUP:s Rapportserie Nr. 6, Mar. 2000.

[6] P. A. Kirschner and M. A. M. Meester, "The laboratory in higher science education: Problems, premises and objectives," Higher Education, vol. 17 , pp. 81-98, 1988.

[7] A. Hofstein and V. N. Lunetta, "The role of the laboratory in science teaching: Neglected aspects of research," Review of Educational Research, vol. 52, no. 2, pp. 201-217, 1982.

[8] J. C. Colosi and C. R. Zales, "Jigsaw cooperative learning improves biology lab courses," BioScience, vol. 48, no. 2, pp. 118-124, Feb. 1998.

[9] B. H. W. Yung, "Three views of fairness in a school-based assessment scheme of practical work in biology," International Journal of Science Education, vol. 23, no. 10, pp. 985-1005, Oct. 2001.

[10] K. J. Topping and S. W. Ehly, "Peer assisted learning: A framework for consultation," Journal of Educational and Psychological Consultation, vol. 12, no. 2, pp. 113-132, Jun. 2001.

[11] D. E. Berry and K. L. Fawkes, "Constructing the Components of a Lab Report Using Peer Review," Journal of Chemical Education, vol. 87, no. 1, pp. 57-61, Jan. 2010.

[12] P. Carlson and F. Berry, "Using computer-mediated peer review in an engineering design course," IEEE Transactions on Professional Communication, vol. 51, no. 3, 2008.

[13] N. Trautmann, "Interactive learning through web-mediated peer review of student science reports," Educational Technology Research and Development, vol. 57, no. 5, pp. 685-704, Oct. 2009.

[14] N. J. Pelaez, "Problem-based writing with peer review improves academic performance in physiology." Advances in physiology education, vol. 26, pp. 174-184, Dec. 2002.

[15] R. Woods, "Iterative processing algorithm to detect biases in assessments," IEEE Transactions on Education, vol. 46, no. 1, pp. 133-141, Feb. 2003.

[16] R. M. Crespo, A. Pardo, and C. Delgado Kloos, "An adaptive strategy for peer review," in Proceedings of ASEE/IEEE Frontiers in Education Conference, Savannah, GA, USA, Oct. 2004.

[17] P. Eibeck, "Criteria for peer-review of engineering courseware on the needs database," IEEE Transactions on Education, vol. 39, no. 3, pp. 381-387, Aug. 1996.

[18] E. Z.-F. Liu, S. Lin, C.-H. Chiu, and S.-M. Yuan, "Web-based peer review: the learner as both adapter and reviewer," Education, IEEE Transactions on, vol. 44, no. 3, pp. 246-251, Aug. 2001.

[19] J. McGourty, "Using multisource feedback in the classroom: a computerbased approach," Education, IEEE Transactions on, vol. 43, no. 2, pp. 120-124, May 2000.

[20] V. Garousi, "Applying peer reviews in software engineering education: An experiment and lessons learned," IEEE Transactions on Education, vol. 53, no. 2, pp. 182-193, 2010.

[21] P. Carlson, F. C. Berry, and D. Voltmer, "Incorporating student peerreview into on introduction to engineering design course," in Proceed ings of ASEE/IEEE Frontiers in Education Conference, Indianapolis, IN, USA, Oct. 2005.

Christian Lundquist received the M.Sc. degree in Automation and Mechatronics Engineering from Chalmers University of Technology, Gothenburg, Sweden, in 2003. He received the Ph.D. degree in 2011, at the Department of Electrical Engineering at Linköping University, Linköping, Sweden, where he now works as a postdoctoral fellow.

Between 2004 and 2007, he worked on active steering systems at ZF Lenksysteme $\mathrm{GmbH}$, Germany. His research interests include sensor fusion and target tracking for automotive applications.

$\mathrm{He}$ is CEO and co-founder of the company SenionLab, developing navigation and positioning solutions for indoor usage. 
Martin A. Skoglund received the M.Sc. degree in Applied Physics and Electrical Engineering in 2008, and the Tech.Lic. degree in Automatic Control in 2011, both from Linköping University, Linköping, Sweden. At present he is working towards a Ph.D. degree at the Division of Automatic Control at the Department of Electrical Engineering, Linköping University, Linköping, Sweden.

His research interests include sensor fusion, visual augmented reality systems, mapping and navigation with particular focus on aerial vehicles.

Karl Granström received the M.Sc. degree in Applied Physics and Electrical Engineering in 2008, and the Tech.Lic. degree in Automatic Control in 2011, both from Linköping University, Linköping, Sweden. At present he is working towards a Ph.D. degree at the Division of Automatic Control at the Department of Electrical Engineering, Linköping University, Linköping, Sweden.

His research interests include sensor fusion, target tracking, mapping and localization, especially for mobile robots.

Torkel Glad was born in Lund, Sweden in 1947. He received his M.Sc. degree in Engineering Physics in 1970 and the Ph.D. degree in Automatic Control in 1976, both from the Lund Institute of Technology, Lund, Sweden. Since 1988, he has been a professor of nonlinear control systems at Linköping University, Linköping, Sweden. His research interests include optimal control, nonlinear systems and differential-algebraic equation models. 